\title{
Effects of $\beta$-carotene on cell viability and antioxidant status of hepatocytes from chronically ethanol-fed rats
}

\author{
Suh-Ching Yang ${ }^{1}$, Chi-Chang Huang ${ }^{1}$, Jan-Show $\mathrm{Chu}^{2}$ and Jiun-Rong $\mathrm{Chen}^{1 *}$ \\ ${ }^{1}$ School of Nutrition and Health Sciences, Taipei Medical University, 250 Wu-Hsin Street, Taipei 110, Taiwan, \\ Republic of China \\ ${ }^{2}$ Department of Pathology, Taipei Medical University, Taipei, Taiwan, Republic of China
}

(Received 4 December 2003 - Revised 5 February 2004 - Accepted 4 April 2004)

\begin{abstract}
The purpose of the present study was to evaluate the effects of $\beta$-carotene on the cell viability and antioxidant status of hepatocytes from chronically ethanol-fed rats. Rats in the ethanol group were given an ethanol-containing liquid diet that provided $36 \%$ of total energy as ethanol, while rats in the control group were fed an isoenergetic diet without ethanol. After 4 weeks, hepatocytes were taken out and cultured for $24 \mathrm{~h}$. Hepatocytes from the rats in the control and ethanol groups were cultured in medium without (HC, HE) or with $\beta$-carotene $(\mathrm{HC}+\mathrm{B}, \mathrm{HE}+\mathrm{B})$. The results showed that lactate dehydrogenase leakage was significantly increased in the HE compared with that in the $\mathrm{HC}$ group. However, lactate dehydrogenase leakage of the $\mathrm{HE}+\mathrm{B}$ group was similar to that of the HC group. When compared with the $\mathrm{HC}$ group, activities of glutathione peroxidase and catalase in the HE group were significantly decreased by 54 and $31 \%$, respectively. Catalase activity in the $\mathrm{HE}+\mathrm{B}$ group was significantly increased by $61 \%$ compared with that in the HE group. However, activities of glutathione reductase and superoxide dismutase showed no difference among the groups. The level of glutathione in the HC $+\mathrm{B}$ and $\mathrm{HE}+\mathrm{B}$ groups was significantly increased to 155 and $143 \%$ compared with those in the HC and HE groups, respectively. The concentration of lipid peroxides showed no difference among the groups. The present results demonstrate that $\beta$-carotene improved the cell viability of hepatocytes, and increased catalase activities and glutathione levels in hepatocytes from chronically ethanol-fed rats.
\end{abstract}

ß-Carotene: Chronic ethanol feeding: Antioxidant status: Hepatocytes

According to the statistics tabulated by the Department of Health, Taiwan (2003), chronic liver disease and cirrhosis together are the sixth leading cause of death in Taiwan. The causation is not only associated with unbalanced dietary patterns but also with excessive consumption of alcohol in recent years. Long-term excessive drinking induces alcoholic liver diseases and psychological damage. Additionally, an unstable mental condition may lead to broken families and several other severe social problems. Therefore, it is important in medical and health research to resolve drinking-induced problems that impact on the health of individuals, families and society.

Ethanol is metabolised to acetaldehyde by some enzymes in the body, including alcohol dehydrogenase, cytochrome P450 2E1, catalase (CAT), xanthine oxidase, etc. Then acetaldehyde is decomposed to acetic acid by acetaldehyde dehydrogenase in the mitochondria. Numerous studies have indicated that an excessive ethanol intake induces the mass production of free radicals in the body, which are considered to be associated with alcoholic liver diseases. Ishii et al. (1997) indicated that the chronic intake of ethanol increases free radical levels, which are produced from the metabolic pathway of ethanol, especially superoxides $\left(\mathrm{O}_{2}^{-}\right)$and $\mathrm{H}_{2} \mathrm{O}_{2}$. Bailey \& Cunningham (1999) indicated that the exposure of hepatocytes to ethanol resulted in an increased production of reactive oxygen species (ROS), which correlated with decreased cell viability. On the other hand, acetaldehyde stimulates the production of neutrophils, and then neutrophils release a large number of free radicals, which can damage hepatocytes and induce alcoholic liver diseases (Williams \& Barry, 1987). Additionally, the chronic intake of ethanol has been shown to induce the production of lipid peroxidation, because of decreasing antioxidant enzyme activities (Rouach et al. 1997). Moreover, many studies have reported that vitamins $\mathrm{A}$ and $\mathrm{E}$ and $\beta$-carotene are reduced in the blood and liver with excessive ethanol intake, and the range of reduction is related to the amount of ethanol administration (Kawase et al. 1989; Leo et al. 1993; Ahmed et al. 1994; Polavarapu et al. 1998). Thus, it was

Abbreviations: CAT, catalase; GOT, glutamate oxaloacetate transaminase; GPT, glutamate pyruvate transaminase; GPx, glutathione peroxidase; GRd, glutathione reductase; $\mathrm{HC}$, control; $\mathrm{HC}+\mathrm{B}$, control $+\beta$-carotene; HE, ethanol-administered; HE $+\mathrm{B}$, ethanol-administered $+\beta$-carotene; 4 -HNE, 4-hydroxy-2(E)-nonenal; LDH, lactate dehydrogenase; MDA, malondialdehyde; ROS, reactive oxygen species; SOD, superoxide dismutase.

* Corresponding author: Professor Jiun-Rong Chen, fax +8862 2737 3112, email syunei@tmu.edu.tw 
thought that antioxidant nutrient supplementation might lower the formation of free radicals produced from excessive ethanol intake by enhancing the body's antioxidant ability. Lieber (1997) reviewed antioxidant nutrient supplementation and suggested that it serves as a new therapy for alcoholic liver disease.

$\beta$-Carotene is viewed as a non-toxic precursor of vitamin A. Also, the strong antioxidant properties of $\beta$-carotene have been proven in several studies (Diplock, 1991). It functions as an efficient singlet oxygen quencher and as a radical-trapping antioxidant at low oxygen pressure to reduce the extent of nuclear damage and to inhibit lipid peroxidation (Palozza \& Krinsky, 1992). It has been reported that the ethanol-induced hepatic depletion of vitamin A could be corrected by $\beta$-carotene supplementation (Ahmed et al. 1994). However, few reports have discussed the antioxidative effects of $\beta$-carotene on ethanol-induced oxidative stress in the liver.

The purpose of the present study was to investigate the direct influences of $\beta$-carotene on the ethanol-induced hepatic damage of antioxidant status. In order to eliminate the conversion and absorption factors of $\beta$-carotene within the intestinal mucosal cells, the primary hepatocytes model was set up to evaluate the effects of $\beta$-carotene on cell viability and antioxidant enzyme activities in hepatocytes from rats, which were chronically administered an ethanol-containing liquid diet.

\section{Materials and methods}

\section{Animals and diets}

The design of the experimental animal model was modified from the studies of Bailey \& Cunningham (1999). Twenty male Sprague-Dawley rats weighing 200-210 g (National Laboratory Animal Breeding and Research Center, National Science Council, Taipei, Taiwan) were used in the present study. Rats were individually housed in a room maintained at $23 \pm 2{ }^{\circ} \mathrm{C}$ with $50-70 \%$ humidity and a $12 \mathrm{~h}$ light-dark cycle. The rats were divided into two groups. One group was not administered ethanol (control group); the other was administered ethanol (ethanol group). The composition of the diets was previously described in detail by Lieber \& DeCarli (1994). The rats in the ethanol group were fed liquid diets with free access that provided $36 \%$ of total energy as ethanol, and the rats in the control group received an isoenergetic amount of the ethanol liquid diet in which the ethanol was replaced with maltose-dextrin. The rats in the control and ethanol groups were fed the experimental liquid diets for 4 weeks.

\section{Liver function and pathology}

At the end of the experimental period, blood was collected from the tail veins of the rats after $10 \mathrm{~h}$ fasting, and glutamate oxaloacetate transaminase (GOT) and glutamate pyruvate transaminase (GPT) activities were measured with commercial kits (RM, 163K; Iatron Laboratories, Tokyo, Japan) to confirm the liver function in each group (Dufour et al. 2000). In addition, one rat in each group was killed and a small piece of liver $(5 \times 2 \mathrm{~mm})$ was removed at death and fixed in $10 \%(\mathrm{v} / \mathrm{v})$ formaldehyde. The samples were stained with haematoxylin and eosin for light microscopy. The pathologist who carried out the histological analysis had no prior knowledge of the different experimental groups.

\section{Preparation of isolated rat hepatocytes}

Hepatocytes were isolated from the rats according to the two-step collagenase perfusion technique described by Berry \& Friend (1969). Isolated cells were cultured as monolayers in William's medium E with $5 \%(\mathrm{w} / \mathrm{v})$ fetal bovine serum and $1 \mu \mathrm{M}$-dexamethasone at a density of $1 \times 10^{5}$ cells $/ \mathrm{ml}$. After $20 \mathrm{~h}$ incubation at $37^{\circ} \mathrm{C}$ in $5 \%$ $\mathrm{CO}_{2}$, the medium was replaced by the medium without $(\mathrm{HC}, \mathrm{HE})$ or with $1 \mu \mathrm{M}-\beta$-carotene $(\mathrm{HC}+\mathrm{B}, \mathrm{HE}+\mathrm{B})$ and continuously cultured for $24 \mathrm{~h}$. $\beta$-Carotene was incorporated with the medium by tetrahydrofuran $(0.5 \%)$ according to the method of Bertram et al. (1991). Then, cells were collected using a scraper and re-suspended in tri(hydroxymethyl)-aminomethane buffer (50 mM-tri(hydroxymethyl)-aminomethane-HCl, 5 mM-EDTA; $\mathrm{pH} 7 \cdot 5$ ) for the following analyses. Thus, hepatocytes from the rats in the control and ethanol groups were cultured in medium without or with $\beta$-carotene.

\section{Lactate dehydrogenase leakage}

The viability of hepatocytes was expressed as the percentage of lactate dehydrogenase (LDH) leakage, which was the LDH content in the culture medium relative to the total LDH content including the culture medium and cytosolic fraction. The LDH level was determined using the method described by Moldeus et al. (1978).

\section{Antioxidative enzyme activities}

Cells in tri(hydroxymethyl)-aminomethane buffer were lysed with a sonicator and centrifuged at $4^{\circ} \mathrm{C}$, and $10000 \mathrm{rpm}$ for 10 min. Then, supernatant fractions were used to determine the antioxidative enzyme activities. Glutathione peroxidase (GPx) activity was measured spectrophotometrically at $340 \mathrm{~nm}$ by the method of Paglia \& Valentine (1967) using a commercial kit (RS 504; Randox Laboratories, Crumlin, Antrim, UK). The activity of GPx is expressed as $\mathrm{mU} / \mathrm{mg}$ protein. GPx activity is expressed as $\mu \mathrm{mol} \mathrm{NADPH}$ oxidised/min. Glutathione reductase (GRd) activity was measured spectrophotometrically at $340 \mathrm{~nm}$ using a commercial kit (Calbiochem 359962; Calbiochem-Novabiochem, La Jolla, CA, USA). GRd activity is also expressed as mU/ $\mathrm{mg}$ protein. CAT activity was determined spectrophotometrically at $240 \mathrm{~nm}$ by the method of Lück (1963). The activity of CAT is expressed as $\mathrm{kU} / \mathrm{mg}$ protein. Superoxide dismutase (SOD) activity was determined spectrophotometrically at $525 \mathrm{~nm}$ by the method of Nebot et al. (1993) using a commercial kit (Calbiochem 574600; Calbiochem-Novabiochem). The activity of SOD is expressed as U/mg protein. The protein content in the hepatocytes was measured by the modified method of Lowry et al. (1951) using a Bio-Rad DC protein assay kit (Bio-Rad Laboratories, Hercules, CA, USA). 


\section{Antioxidants levels}

The concentration of GSH in the hepatocytes was measured spectrophotometrically at $400 \mathrm{~nm}$ using a commercial kit (Calbiochem 354102; Calbiochem-Novabiochem) according to the method of Anderson (1989).

Concentrations of $\beta$-carotene and retinol in the hepatocytes and medium were measured by reverse-phase HPLC (Shimadzu LC-10A HPLC Pump, Shimadzu SPD10AV UV/Vis Detector; Shimadzu, Tokyo, Japan) using a $4.6 \times 250 \mathrm{~mm} \mathrm{C}_{18}$ column $(5 \mu \mathrm{m}$, Vydac 201TP54) according to the method of Wei et al. (1998). The concentration of $\beta$-carotene was measured at $452 \mathrm{~nm}$ under the mobile phase of methanol, acetonitrile and $\mathrm{H}_{2} \mathrm{O}$ (88:9:3, by vol.). The concentration of retinol was measured at $325 \mathrm{~nm}$ under the mobile phase of methanol. Data were analysed by SISC-LAB chromatographic analysis software (Scientific Information Service Corp., Taipei, Taiwan).

\section{Lipid peroxidation}

The concentration of lipid peroxides in the hepatocytes was assessed colorimetrically at $586 \mathrm{~nm}$ using a commercial kit (Calbiochem 437634; Calbiochem-Novabiochem) (Esterbauer \& Cheeseman, 1990). The cytosolic fraction $(200 \mu \mathrm{l})$ was mixed with $650 \mu \mathrm{l}$ reagent $1 \quad(7.7 \mathrm{nmol}$ $N$-methyl-2-phenylindole/l in $75 \%$ acetonitrile and $25 \%$ methanol) and $150 \mu \mathrm{l}$ reagent $2(15.4 \mathrm{~mol}$ methanesulfonic acid/l) at $45^{\circ} \mathrm{C}$ for $40 \mathrm{~min}$. The levels of malondialdehyde (MDA) and 4-hydroxy-2(E)-nonenal (4-HNE) endproducts derived from the peroxidation of PUFA and related esters were measured at $586 \mathrm{~nm}$.

\section{Statistical analysis}

All data are expressed as means and standard deviations. The data were analysed by unpaired Student's $t$ test to determine the effects of ethanol on GOT and GPT activities in the rats. Also, the data were analysed by two-way ANOVA to determine the effects of ethanol and $\beta$-carotene on the antioxidative status of primary hepatocytes from the control and ethanol-administered rats. Fisher's least significant difference test was used to make post hoc comparisons if a main effect was demonstrated. SAS software (version 6.12; SAS Institute, Inc., Cary, NC, USA) was used to analyse all data. Statistical significance was assigned at the $P<0.05$ level.

\section{Results}

Energy intakes in the control and ethanol groups were 257.5 (SD 0.4) and 254.1 (SD 0.4) kJ/d, respectively. And, the average alcohol intake in the ethanol group was 2.62 (SD 0.03) $\mathrm{g} / \mathrm{d}$. Initial body weight was $200 \cdot 4$ (SD 8.0) $\mathrm{g}$ in the control group and 200.2 (SD 5.1) $\mathrm{g}$ in the ethanol group. After 4 weeks, the final body weight of the ethanol group (276.8 (SD 31.0) g) was significantly lower $(P<0.05)$ than that of the control group (313.4 (SD 7.5) g).

GOT activities of the control and ethanol groups were 66 (SD 10) and 82 (SD 1) karmen units. GPT activities of the control and ethanol groups were 18 (SD 4) and 29 (SD 5) karmen units. Compared with the control group, GOT and GPT activities had significantly increased $(P<0 \cdot 05)$ by 24 and $61 \%$ in the ethanol group, respectively. From the light micrograph of liver, fat accumulation was observed in the ethanol group (Fig. 1).

LDH leakage is shown in Table 1. LDH leakage of the HE group had significantly increased $(P<0.05)$ when compared with that of the $\mathrm{HC}$ group. In contrast, LDH leakage in the $\mathrm{HE}+\mathrm{B}$ group was nearly the same as that of the $\mathrm{HC}$ group, and significantly lower $(P<0.05)$ than that of the HE group.

Table 2 shows the antioxidative enzyme activities. The HE group had significantly lower $(-54 \% ; P<0.05)$ GPx activities than the $\mathrm{HC}$ group. Furthermore, the $\mathrm{HE}+\mathrm{B}$ group had significantly decreased $(-54 \% ; P<0.05)$ GPx activities than the $\mathrm{EC}+\mathrm{B}$ group, but showed no difference when compared with the HE group. The CAT activity of the HE group was significantly reduced (-31\%; $P<0.05)$ compared with that of the HC group, but it was significantly elevated by $61 \%$ in the $\mathrm{HE}+\mathrm{B}$ group compared with the HE group $(P<0 \cdot 05)$. However, there was no change in the GRd and SOD activities of any group.

Concentrations of GSH and lipid peroxides are shown in Table 3. The GSH level showed no changes between the $\mathrm{HC}$ and HE groups. However, the level of GSH in the $\mathrm{HC}+\mathrm{B}$ group had significantly increased $(P<0.05)$ by 155 and $143 \%$ compared with those of the $\mathrm{HC}$ and $\mathrm{HE}$ groups, respectively. However, there were no differences in the MDA and 4-HNE levels in any group.

Tables 4 and 5 show the levels of $\beta$-carotene and retinol in hepatocytes and medium. $\beta$-Carotene levels in the $\mathrm{HC}+\mathrm{B}$ and $\mathrm{HE}+\mathrm{B}$ groups had significantly increased $(P<0.05)$ compared with those of the $\mathrm{HC}$ and $\mathrm{HE}$ groups in both hepatocytes and medium. The retinol concentration of the $\mathrm{HC}+\mathrm{B}$ and $\mathrm{HE}+\mathrm{B}$ groups had significantly increased $(P<0.05)$ compared with those of the HC and HE groups in hepatocytes. However, the retinol level of the medium in the HE group was significantly reduced $(-14 \%$; $P<0.05)$ compared with that of the $\mathrm{HC}$ group, and those of the $\mathrm{HC}+\mathrm{B}$ and $\mathrm{HE}+\mathrm{B}$ groups had significantly increased $(P<0.05)$. Moreover, the retinol level of the medium in the $\mathrm{HE}+\mathrm{B}$ group was significantly lower $(-12 \% ; P<0.05)$ compared with that of the $\mathrm{HC}+\mathrm{B}$ group.

\section{Discussion}

Chronic ethanol consumption results in the formation of oxygen free radicals and lipid peroxidation (Reinke et al. 1987). In the present study, $\beta$-carotene was used to improve the cell viability and antioxidant status in hepatocytes from chronically ethanol-fed rats.

In the present study, it was found that ethanol consumption in the ethanol group was similar to that reported in other previous reports (Lieber \& DeCarli, 1994; Navder et al. 1997). On the other hand, the isoenergetic substitution of carbohydrates by ethanol resulted in a lower weight gain despite similar energy intakes as also previously reported (Pirola \& Lieber, 1975). This lower body-weight gain has been attributed to induction of the microsomal ethanol-oxidising system, increased sympathetic tone and associated thermogenesis and/or enhanced 
ATP breakdown secondary to acetate production from ethanol (Cunningham \& Spach, 1987). Ethanol consumption for 4 weeks by rats led to high GOT and GPT activities and fatty changes in the liver, which might have been due to an enhanced mobilisation of NEFA from adipose tissue and the increased hepatic biosynthesis of lipids as previously suggested (Fig. 1) (Lieber, 1991).

LDH is an enzyme that exists in many tissues and organs, such as the heart, muscle, kidney, liver, etc. When those tissues or organs are damaged, LDH is released into the blood from cells. Therefore, LDH leakage can be used to indicate cell viability. In the present study, the viability of hepatocytes was monitored by the release of LDH into the medium; that is to say, higher LDH leakage was interpreted as lower viability of hepatocytes. Hepatocytes from the ethanol-fed rats showed higher LDH leakage than those from the control rats (Table 1; HC $v$. HE). This suggests that chronic ethanol administration might reduce the cell viability of hepatocytes, which might be due to the oxidative stress from ethanol (Bailey $\&$ Cunningham, 1999). However, $\beta$-carotene significantly decreased LDH leakage when it was added to the medium (Table 1; HE v. HE + B). Similar to the present results, previous in vitro studies have shown that $\beta$-carotene can decrease LDH leakage of hepatocytes by means of reducing ROS production (Ek et al. 1994; Martin et al. 1996; Lawlor \& O’Brien, 1997).

The metabolism of ethanol is believed to result in an increased production of ROS, especially superoxide and $\mathrm{H}_{2} \mathrm{O}_{2}$, and the removal of these toxic species is thought to be a vital initial step in ensuring cell survival during ethanol intoxication (Nordmann et al. 1992). Four major antioxidant enzymes available to the cell during ethanolinduced oxidant stress include GPx, GRd, CAT and SOD. Schisler \& Singh (1989) reported that GPx, CAT and SOD activities in ethanol-treated animals, including five inbred strains of mice and Sprague-Dawley rats, were generally reduced in comparison with those of their
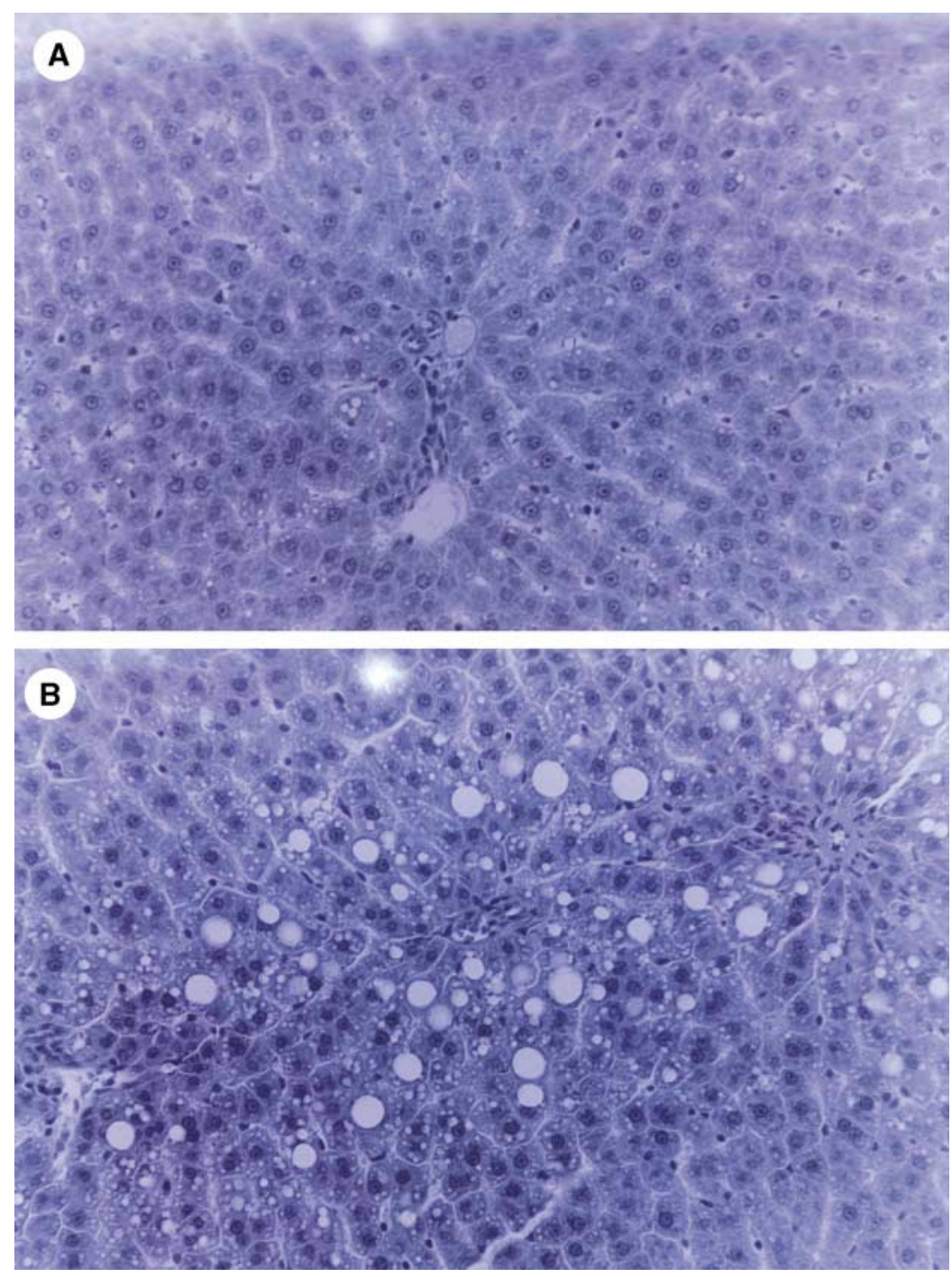

Fig. 1. Effects of ethanol on liver pathology between control and ethanol groups. (A), Section of liver from a rat fed the control diet for 4 weeks showing normal histology with no evidence of pathological change (haematoxylin and eosin, magnification $\times 200$ ); (B), section of liver from a rat fed ethanol for 4 weeks showing the presence of macrovesicular and microvesicular fat accumulation (haematoxylin and eosin, magnification $\times 200$ ). 
Table 1. Effect of $\beta$-carotene on lactate dehydrogenase (LDH) leakage in primary rat hepatocytes* (Mean values and standard deviations of three replicate assays)

\begin{tabular}{lcr}
\hline & \multicolumn{2}{c}{ LDH (\%) } \\
\cline { 2 - 3 } Groupt & Mean & SD \\
\hline $\mathrm{HC}$ & $41^{\mathrm{a}}$ & 2 \\
$\mathrm{HC}+\mathrm{B}$ & $43^{\mathrm{a}}$ & 1 \\
$\mathrm{HE}$ & $69^{\mathrm{b}}$ & 9 \\
$\mathrm{HE}+\mathrm{B}$ & $40^{\mathrm{a}}$ & 4 \\
\hline
\end{tabular}

${ }^{a, b}$ Mean values with unlike superscript letters were significantly different $(P<0.05)$.

${ }^{*}$ For details of procedures, see p. 210.

† Hepatocytes from the control group were cultured in medium without $(\mathrm{HC})$ or with $\beta$-carotene $(\mathrm{HC}+\mathrm{B})$, and hepatocytes from the ethanol group were also cultured in medium without $(\mathrm{HE})$ or with $\beta$-carotene $(\mathrm{HE}+\mathrm{B})$.

matched controls. Polavarapu et al. (1998) also suggested that GPx, CAT and SOD activities showed an inverse correlation with severity of pathological injury in rats fed ethanol. However, Oh et al. (1998) reported that chronic ethanol feeding resulted in a lower activity of GPx with significantly higher activities of GRd and CAT.

The present results indicated that GPx and CAT activities showed significant reductions, but GRd and SOD showed no changes in the hepatocytes from the chronically ethanol-fed rats (Table 2; HC $v$. HE). Both GPx and CAT can react with $\mathrm{H}_{2} \mathrm{O}_{2}$. GPx is thought to be more active in the removal of $\mathrm{H}_{2} \mathrm{O}_{2}$ because of its dual location (mitochondria and cytosol) (Diplock, 1991). Therefore, this theory suggests that GPx should be more sensitive and more easily alterable than CAT in a situation of chronic ethanol intake.

Also, it has been reported that chronic ethanol feeding results in an increased (Polavarapu et al. 1998), decreased (Comport et al. 1973), or unchanged (Shaw et al. 1981) hepatic GSH content. In the present study, there were no significant changes in the GSH content of hepatocytes from the ethanol-fed rats (Table 3; HC $v$. HE). This might be one of the reasons why there were different changes in antioxidant enzyme activities among different studies. The discrepancies in the total GSH levels in the livers of rats chronically fed ethanol might have originated from differences in the strains of rats used and the dose, duration and route of ethanol administration among different studies. The most acceptable concept is that chronic ethanol intake significantly increases the rate of GSH turnover (Morton \& Mitchell, 1985). Therefore, the GSH:GSSG ratio must be determined in future studies.

Lipid peroxidation induced by long-term ethanol intake results not only from an increased ROS production but also from the enhanced generation of acetaldehyde (Müller \& Sies, 1982). However, another mechanism that promotes lipid peroxidation is GSH depletion. Many reports have demonstrated that chronic ethanol intake promotes the accumulation of lipid peroxidation (Shaw et al. 1981; Müller \& Sies, 1982; Polavarapu et al. 1998), but the present results did not show an alteration of the MDA + 4-HNE contents of hepatocytes from the ethanol-fed rats (Table 3; HC $v$. HE). We speculated that the unchanged GSH level was one of the reasons why the MDA + 4-HNE contents showed no striking changes.

Carotenoids have been found to inhibit free radicalinduced lipid peroxidation (Krinsky \& Deneke, 1982; Krinsky 1989), and $\beta$-carotene is one of the most efficient

Table 3. Effect of $\beta$-carotene on reduced glutathione and lipid peroxide concentrations in primary rat hepatocytes* (Mean values and standard deviations of three replicate assays)

\begin{tabular}{|c|c|c|c|c|}
\hline \multirow[b]{2}{*}{ Group† } & \multicolumn{2}{|c|}{$\mathrm{GSH}(\mu \mathrm{M})$} & \multicolumn{2}{|c|}{$\begin{array}{c}\text { MDA + 4-HNE } \\
(\mu \mathrm{M})\end{array}$} \\
\hline & Mean & SD & Mean & SD \\
\hline $\mathrm{HC}$ & $0.27^{\mathrm{a}}$ & 0.26 & $6 \cdot 21^{a}$ & 0.20 \\
\hline $\mathrm{HC}+\mathrm{B}$ & $0.69^{b}$ & 0.11 & $5 \cdot 32^{a}$ & 0.68 \\
\hline & $0.21^{a}$ & 0.10 & $6 \cdot 21^{a}$ & 0.36 \\
\hline $\mathrm{HE}+\mathrm{B}$ & $0.51^{b}$ & 0.18 & $5 \cdot 71^{a}$ & 1.29 \\
\hline
\end{tabular}

MDA, malondialdehyde; 4-HNE, 4-hydroxy-2(E)-nonenal.

${ }^{a, b}$ Mean values within a column with unlike superscript letters were significantly different $(P<0.05)$.

${ }^{*}$ For details of procedures, see p. 210.

†Hepatocytes from the control group were cultured in medium without $(\mathrm{HC})$ or with $\beta$-carotene $(\mathrm{HC}+\mathrm{B})$, and hepatocytes from the ethanol group were also cultured in medium without $(\mathrm{HE})$ or with $\beta$-carotene $(\mathrm{HE}+\mathrm{B})$.

Table 2. Effects of $\beta$-carotene on antioxidant enzymes glutathione peroxidase (GPx), glutathione reductase (GRd), catalase (CAT) and superoxide dismutase (SOD) activities in primary rat hepatocytes*

(Mean values and standard deviations of three replicate assays)

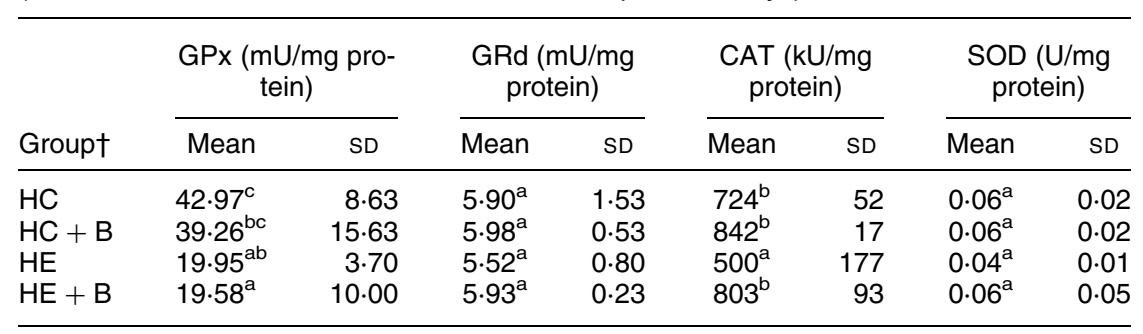

${ }^{a, b, c}$ Mean values within a column with unlike superscript letters were significantly different $(P<0.05)$.

* For details of procedures, see p. 210.

† Hepatocytes from the control group were cultured in medium without $(\mathrm{HC})$ or with $\beta$-carotene $(\mathrm{HC}+\mathrm{B})$, and hepatocytes from the ethanol group were also cultured in medium without $(\mathrm{HE})$ or with $\beta$-carotene (HE $+\mathrm{B})$. 
Table 4. Effects of $\beta$-carotene on $\beta$-carotene concentrations of hepatocytes and medium in each group*

(Mean values and standard deviations of three replicate assays)

\begin{tabular}{|c|c|c|c|c|}
\hline \multirow[b]{3}{*}{ Group } & \multicolumn{4}{|c|}{$\beta$-Carotene concentration } \\
\hline & \multicolumn{2}{|c|}{$\begin{array}{l}\text { Hepatocytes } \\
\text { (nmol/107cells) }\end{array}$} & \multicolumn{2}{|c|}{$\begin{array}{c}\text { Medium } \\
\left(10^{-10} \mathrm{~mol} / \mathrm{ml}\right)\end{array}$} \\
\hline & Mean & SD & Mean & SD \\
\hline $\begin{array}{l}\mathrm{HC} \\
\mathrm{HC}+\mathrm{B} \\
\mathrm{HE} \\
\mathrm{HE}+\mathrm{B}\end{array}$ & $\begin{array}{l}0^{\mathrm{b}} \\
5 \cdot 96^{\mathrm{a}} \\
0^{\mathrm{b}} \\
5 \cdot 49^{\mathrm{a}}\end{array}$ & $\begin{array}{l}0 \\
0.82 \\
0 \\
0.58\end{array}$ & $\begin{array}{l}0^{\mathrm{b}} \\
2 \cdot 46^{\mathrm{a}} \\
0^{\mathrm{b}} \\
2 \cdot 25^{\mathrm{a}}\end{array}$ & $\begin{array}{l}0 \\
0.49 \\
0 \\
0.40\end{array}$ \\
\hline \multicolumn{5}{|c|}{$\begin{array}{l}\text { a,b Mean values within a column with unlike superscript letters were } \\
\text { significantly different }(P<0.05) \text {. } \\
\text { * For details of procedures, see } \mathrm{p} .210 \text {. } \\
\text { † Hepatocytes from the control group were cultured in medium with- } \\
\text { out }(\mathrm{HC}) \text { or with } \beta \text {-carotene }(\mathrm{HC}+\mathrm{B}) \text {, and hepatocytes from the } \\
\text { ethanol group were also cultured in medium without (HE) or with } \\
\beta \text {-carotene (HE }+\mathrm{B}) \text {. }\end{array}$} \\
\hline
\end{tabular}

quenchers of singlet oxygen (Lomnitski et al. 1993). $\beta$-Carotene may also prevent lipid peroxidation through specific enzyme inhibition (Palozza \& Krinsky, 1991; Lomnitski et al. 1993). However, the present study demonstrated that $\beta$-carotene improved the CAT activity as well as the GSH level when it was added into the medium of hepatocytes from the ethanol-fed rats (Tables 2 and 3; HE $v$. HE $+\mathrm{B}$ ). The present results suggest that higher GSH levels due to $\beta$-carotene treatment might reduce $\mathrm{H}_{2} \mathrm{O}_{2}$ production and indirectly improve CAT activity. Furthermore, the lipid peroxide contents slightly decreased without statistical significance in the hepatocytes treated with $\beta$-carotene (Table 3; $\mathrm{HC} v . \mathrm{HC}+\mathrm{B}, \mathrm{HE} v$. $\mathrm{HE}+\mathrm{B})$. A study in guinea-pigs noted a protective effect against lipid peroxidation when animals were pre-treated with $\beta$-carotene (Kunert \& Tappel, 1983), and in rats it was reported that $\beta$-carotene inhibited MDA production in a concentration-dependent manner (Kim-Jun, 1993). However, in rats, Alam \& Alam (1983) noted no change in either blood or tissue lipid peroxides after the ingestion of $180 \mathrm{mg} \beta$-carotene $/ \mathrm{kg}$ per $\mathrm{d}$ for 11 weeks. In any event, the question remains as to whether the combination of alcohol and $\beta$-carotene may be useful for the prevention of lipid peroxidation without producing some signs of toxicity. Leo et al. (1993) reported that ethanol-induced oxidative stress was improved only by high-dosage $\beta$-carotene supplementation. Leo et al. (1993) also concluded that the dosage of $\beta$-carotene was the key point in the improvement of the ethanol-induced oxidative stress including lipid peroxidation. Therefore, in the present study, if the $\beta$-carotene content in the medium is elevated, the reduced range in the lipid peroxide contents may be more evident.

Concerning the $\beta$-carotene content of the hepatocytes, it was demonstrated that the $\beta$-carotene levels were zero in the control cells (Table 4; HC and HE). This means that the $\beta$-carotene could not have been endogenously produced in the hepatocytes. When $\beta$-carotene was supplied, the $\beta$-carotene concentration was significantly increased in the cells (Table 4; $\mathrm{HC}+\mathrm{B}$ and $\mathrm{HE}+\mathrm{B}$ ). In addition, retinol was detectable in hepatocytes and medium, and its
Table 5. Effects of $\beta$-carotene on retinol concentrations of hepatocytes and medium in each group*

(Mean values and standard deviations of three replicate assays)

\begin{tabular}{|c|c|c|c|c|}
\hline \multirow[b]{3}{*}{ Group† } & \multicolumn{4}{|c|}{ Retinol concentration } \\
\hline & \multicolumn{2}{|c|}{$\begin{array}{c}\text { Hepatocytes } \\
\left(10^{-10} \mathrm{~mol} / 10^{7} \text { cells }\right)\end{array}$} & \multicolumn{2}{|c|}{ Medium (nmol/ml) } \\
\hline & Mean & SD & Mean & SD \\
\hline $\begin{array}{l}\mathrm{HC} \\
\mathrm{HC}+\mathrm{B} \\
\mathrm{HE} \\
\mathrm{HE}+\mathrm{B}\end{array}$ & $\begin{array}{l}5 \cdot 32^{\mathrm{a}} \\
7.50^{\mathrm{b}} \\
5 \cdot 32^{\mathrm{a}} \\
6 \cdot 20^{\mathrm{b}}\end{array}$ & $\begin{array}{l}0.34 \\
0.31 \\
0.15 \\
0.71\end{array}$ & $\begin{array}{l}8.85^{b} \\
9.88^{c} \\
7.59^{a} \\
8.68^{b}\end{array}$ & $\begin{array}{l}0.3 \\
0.98 \\
0.30\end{array}$ \\
\hline
\end{tabular}

${ }^{a, b, c}$ Mean values within a column with unlike superscript letters were significantly different $(P<0.05)$.

${ }^{*}$ For details of procedures, see p. 210.

† Hepatocytes from the control group were cultured in medium without $(\mathrm{HC})$ or with $\beta$-carotene $(\mathrm{HC}+\mathrm{B})$, and hepatocytes from the ethanol group were also cultured in medium without $(\mathrm{HE})$ or with $\beta$-carotene $(\mathrm{HE}+\mathrm{B})$.

levels were significantly reduced in the ethanol-fed rats' hepatocytes whether treated with $\beta$-carotene or not (Table 5; HC $v$. HE, $\mathrm{HC}+\mathrm{B} v$. HE $+\mathrm{B}$ ). The present results suggest that $\beta$-carotene might enter hepatocytes and be converted to retinol, and the hepatocytes from the ethanol-fed rats consumed more retinol than those from the control rats. This phenomenon agrees with previous studies, that is, ethanol intake induces the depletion of hepatic vitamin A (Kawase et al. 1989; Leo et al. 1993; Ahmed et al. 1994; Polavarapu et al. 1998).

In previous studies (Leo et al. 1993; Ahmed et al. 1994), it has been demonstrated that $\beta$-carotene could alleviate ethanol-induced liver damage by correcting the retinol depletion. However, the present study indicates that cell viability, CAT activities, GSH levels and retinol contents were improved when $\beta$-carotene was directly supplied to the hepatocytes of the chronically ethanol-fed rats. This means that $\beta$-carotene could attenuate the oxidative stress induced by chronic ethanol intake. On the basis of the present study, the dosage of $\beta$-carotene must be reconsidered, when $\beta$-carotene is provided in food or supplements during chronic ethanol ingestion, and an in vivo study is essential in the future.

\section{References}

Ahmed S, Leo MA \& Lieber CS (1994) Interaction between alcohol and beta-carotene in patients with alcoholic liver disease. Am J Clin Nutr 60, 430-436.

Alam SQ \& Alam BS (1983) Lipid peroxide, $\alpha$-tocopherol and retinoid levels in plasma and liver of rats fed diets containing $\beta$-carotene and 13-cis-retinoic acids. J Nutr 113, 2608-2614.

Anderson ME (1989) Enzymatic and chemical methods for the determination of glutathione. In Glutathione: Chemical, Biochemical and Medical Aspect, vol. A. pp. 339-365 [D Dolphin, $\mathrm{R}$ Poulson and O Avramovic, editors]. New York: John Wiley \& Sons.

Bailey SM \& Cunningham CC (1999) Effect of dietary fat on chronic ethanol-induced oxidative stress in hepatocytes. Alcohol Clin Exp Res 23, 1210-1218.

Berry MN \& Friend DS (1969) High-yield preparation of isolated rat liver parenchymal cells: a biochemical and fine structural study. J Cell Biol 43, 506-520. 
Bertram JS, Pung A, Churley M, Kappock TJ, Wilkins LR \& Conney RV (1991) Diverse carotenoids protect against chemically induced neoplastic transformation. Carcinogenesis 12, 671-678.

Comport M, Benedetti A \& Cheli F (1973) Studies on in vitro peroxidation of liver lipids in ethanol-treated rats. Lipids $\mathbf{8}$, 498-502.

Cunningham CC \& Spach PI (1987) The effect of chronic ethanol consumption on the lipids in liver mitochondria. Ann N Y Acad Sci 492, 181-192.

Department of Health, Taiwan (2003) Analysis of the Main Causes of Death in Taiwan for the Year 2002. Taiwan: Department of Health.

Diplock AT (1991) Antioxidant nutrients and disease prevention: an overview. Am J Clin Nutr 53, 189S-193S.

Dufour DR, Lott JA, Nolte FS, Gretch DR, Koff RS \& Seeff LB (2000) Diagnosis and monitoring of hepatic injury. I Performance characteristics of laboratory tests. Clin Chem $\mathbf{4 6}$ 2027-2049.

Ek B, Halberg C, Sjogren KG \& Hjalmarson A (1994) Reoxygenation-induced cell damage of isolated neonatal rat ventricular myocytes can be reduced by chain-breaking antioxidants. Free Radic Biol Med 16, 117-121.

Esterbauer H \& Cheeseman KH (1990) Determination of aldehydic lipid peroxidation products: malonaldehyde and 4-hydroxynonenal. Methods Enzymol 186, 407-421.

Ishii H, Kurose I \& Kato S (1997) Pathogenesis of alcoholic liver disease with particular emphasis on oxidative stress. J Gastroenterol Hepatol 12, 272-282.

Kawase T, Kato S \& Lieber CS (1989) Lipid peroxidation and antioxidant defense system in rat liver after chronic ethanol feeding. Hepatology 10, 815-821.

Kim-Jun H (1993) Inhibitory effects of $\alpha$ and $\beta$-carotene in croton oil-induced or enzymatic lipid peroxidation and hydroperoxide production in mouse skin epidermis. Int $J$ Biochem $\mathbf{2 5}$, 911-915.

Krinsky NI (1989) Antioxidant functions of carotenoids. Free Radic Biol Med 7, 617-635.

Krinsky NI \& Deneke SM (1982) Interaction of oxygen and oxyradicals with carotenoids. J Natl Cancer Inst 69, 205-210.

Kunert KJ \& Tappel AL (1983) The effect of vitamin C and $\beta$ carotene on in vitro lipid peroxidation in guinea pig as measured by pentane and ethane production. Lipids 11, 271-274.

Lawlor SM \& O'Brien NM (1997) Modulation of paraquat toxicity by $\beta$-carotene at low oxygen partial pressure in chicken embryo fibroblasts. Br J Nutr 77, 133-140.

Leo MA, Rosman AS \& Lieber CS (1993) Differential depletion of carotenoids and tocopherol in liver disease. Hepatology 17, 977-986.

Lieber CS (1991) Hepatic metabolic and toxic effect of ethanol: 1991 update. Alcohol Clin Exp Res 15, 573-592.

Lieber CS (1997) Roles of oxidative stress and antioxidant therapy in alcoholic and nonalcoholic liver diseases. Adv Pharmacol 38, 601-628.

Lieber CS \& DeCarli LM (1994) Animal models of chronic ethanol toxicity. Methods Enzymol 233, 585-594.

Lomnitski L, Bar-Natan R, Sklan D \& Grossman S (1993) The interaction between $\beta$-carotene and lipoxygenase in plant and animal systems. Biochim Biophys Acta 1167, 331-338.

Lowry OH, Rosebrough NJ, Farr A \& Randall RJ (1951) Protein measurement with the Folin phenol reagent. J Biol Chem 193, $265-275$.

Lück H (1963) Catalase. In Methods of Enzymatic Analysis, pp. 885-888. [HU Bergmeyer, editor]. New York: Academic Press.

Martin KR, Faila ML \& Smith JC (1996) Beta-carotene and lutein protect HepG2 human liver cells against oxidant-induced damage. J Nutr 126, 2098-2106.

Moldeus P, Hogberg J \& Orrenius S (1978) Isolation and use of liver cells. Methods Enzymol 52, 60-71.

Morton S \& Mitchell MC (1985) Effects of chronic ethanol feeding on glutathione turnover in the rat. Biochem Pharmacol 34, $1559-1563$.

Müller A \& Sies H (1982) Role of alcohol dehydrogenase activity and the acetaldehyde in ethanol-induced ethane and pentane production by isolated perfused rat liver. Biochem $J$ 206, $153-156$.

Navder KP, Baraona E \& Lieber CS (1997) Polyenylphosphatidylcholine attenuates alcohol-induced fatty liver and hyperlipidemia in rats. Nutrition 127, 1800-1806.

Nebot C, Moutet M, Huet P, Xu JZ, Yadan JC \& Chaudiere J (1993) Spectrophotometric assay of superoxide dismutase activity based on the activated autoxidation of a tetracyclic catechol. Anal Biochem 214, 442-451.

Nordmann R, Ribiere C \& Rouach H (1992) Implication of free radical mechanisms in ethanol-induced cellular injury. Free Radic Biol Med 12, 219-240.

Oh SI, Kim CI, Chun HJ \& Park SC (1998) Chronic ethanol consumption affects glutathione status in rat liver. $J$ Nutr $\mathbf{1 2 8}$, $758-763$.

Paglia DE \& Valentine WN (1967) Studies on the quantitative and qualitative characterization of erythrocyte glutathione peroxidase. J Lab Clin Med 70, 158-169.

Palozza P \& Krinsky NI (1991) The inhibition of radical-initiated peroxidation of microsomal lipids by both $\alpha$-tocopherol and $\beta$ carotene. Free Radic Biol Med 11, 407-414.

Palozza P \& Krinsky NI (1992) Antioxidant effects of carotenoids in vivo and in vitro: an overview. Methods Enzymol 213, 403-420.

Pirola RC \& Lieber CS (1975) Energy wastage in rats given drugs that induce microsomal enzyme. J Nutr 105, 1544-1548.

Polavarapu R, Spitz DR, Sim JE, Follansbee MH, Oberley LW, Rahemtulla A \& Nanji AA (1998) Increased lipid peroxidation and impaired antioxidant enzyme function is associated with pathological liver injury in experimental alcoholic liver disease in rats fed diets high in corn oil and fish oil. Hepatology 27, $1317-1323$

Reinke LA, Lai EK, DuBose CM \& MacCay PB (1987) Reactive free radical generation in vivo in heart and liver of ethanol-fed rats: correlation with radical formation in vitro. Proc Natl Acad Sci U S A 84, 9223-9227.

Rouach H, Fataccioli V, Gentil M, French SW, Morimoto M \& Nordmann R (1997) Effect of chronic ethanol feeding on lipid peroxidation and protein oxidation in relation to liver pathology. Hepatology 25, 351-355.

Schisler NJ \& Singh SM (1989) Effect of ethanol in vivo on enzymes which detoxify oxygen free radicals. Free Radic Biol Med 7, 117-123.

Shaw S, Jayatilleke E, Ross WA, Gordon ER \& Lieber CS (1981) Ethanol-induced lipid peroxidation: potentiation by long-term alcohol feeding and attenuation by methionine. J Lab Clin Med 98, 417-422.

Wei RR, Wamer WG, Lambert LA \& Kornhauser A (1998) $\beta$-Carotene uptake and effects on intracellular levels of retinal in vitro. Nutr Cancer 30, 53-58.

Williams AJ \& Barry RE (1987) Free radical generation by neutrophils: a potential mechanism of cellular injury in acute alcoholic hepatitis. Gut 28, 1157-1161. 